\title{
Explantes teciduais: um modelo redescoberto na experimentação animal
}

\section{Tissue explants: a model rediscovered in animal experiments}

\author{
Karina Maria Basso ${ }^{1}$; Ana Paula Frederico Rodrigues Loureiro Bracarense ${ }^{2 *}$
}

\section{Resumo}

A técnica ex vivo foi desenvolvida na década de 30 e, nos últimos anos, em decorrência de aspectos éticos e legais em experimentos laboratoriais, foi redescoberta como técnica eficaz. O suíno é frequentemente utilizado como modelo animal, uma vez que esta espécie compartilha alta similaridade em vários sistemas orgânicos com o ser humano. Explantes de intestino, pele, articulação, pulmão e brônquios de suínos têm sido utilizados na experimentação animal, com finalidades diversas, como a avaliação dos efeitos de substâncias tóxicas, carcinogênicas, terapêuticas, agentes biológicos ou testes de sensibilidade. A utilização de explantes permite minimizar problemas éticos e a falta de amostras de origem humana que a pesquisa encontra. No entanto, uma das maiores limitações da técnica é o tempo de viabilidade celular devido a hipóxia a qual o tecido é submetido durante o tempo de cultivo. Por outro lado, o método permite procedimentos experimentais mais controlados associados à redução no número de animais, ampliando as áreas de investigação científica.

Palavras-chave: Ex vivo, cultivo de orgão, suínos

\begin{abstract}
The ex vivo technique was developed in the 30's and in recent years, due to ethical and legal issues in laboratory experiments, was rediscovered as effective technique. Pigs are often used as animal model in this technique due to the high similarity in various organ systems with humans. Explants of intestine, skin, joint, lung and bronchus of pigs have been used in animal experiments, with different purposes, such as evaluating the effects of toxic, carcinogenic, therapeutic, and biological agents or sensitivity tests. The use of explants minimizes ethical problems and lack of human samples, that often affect researches. A major limitation of the technique is time cell viability, due to hypoxia that occurs during incubation. Moreover, the method allows more controlled experimental procedures associated with a reduction in the number of animals, expanding the areas of scientific research.
\end{abstract}

Key words: Ex vivo, organ culture, swine

\footnotetext{
${ }^{1}$ Discente, Programa de Pós-Graduação em Ciência Animal, Universidade Estadual de Londrina, UEL, Londrina, PR. E-mail: karinavet.basso@gmail.com

${ }^{2}$ Prof ${ }^{a}$ Associado, UEL, Londrina, PR. E-mail: anaue102@yahoo.com.br

* Autor para correspondência
} 


\section{Introdução}

Por apresentar características semelhantes ao ser humano, cada vez mais o suíno tem sido empregado como modelo animal em estudos laboratoriais. Estas semelhanças são observadas em diversos sistemas orgânicos, sendo os sistemas gastrointestinal, cardiovascular e pulmonar os mais utilizados em pesquisas laboratoriais (GUILLOTEAU et al., 2010). Outros órgãos como a pele, o fígado e a vesícula biliar dos suínos também são utilizados em modelos experimentais para seres humanos (SWINDLE; SMITH, 1998).

O trato gastrointestinal é a primeira barreira física contra agentes patogênicos, assim como substâncias químicas, sendo ainda a principal via de absorção de nutrientes, água e medicamentos para o corpo e fundamental para o desenvolvimento e manutenção do organismo vivo (GARTNER; HIATT, 2007). A similaridade do trato gastrointestinal do homem e do suíno se dá em vários aspectos como digestão, absorção e metabolismo, o que favorece a utilização do suíno em experimentos laboratoriais, em relação a outros animais (GUILLOTEAU et al., 2010). Tempo de transporte pelo trato gastrointestinal, modo de absorção de nutrientes, transporte de íons e motilidade intestinal semelhantes ao ser humano também são fatores que favorecem a utilização dos suínos em relação a outros animais (SWINDLE; SMITH, 1998). Essas características compartilhadas provavelmente são devido ao tipo de dieta onívora que as duas espécies apresentam.

Estudos relacionados ao sistema cardiovascular e pulmonar de seres humanos podem utilizar o suíno como modelo animal. O tamanho e a morfologia são próximos ao do ser humano, além da semelhança fisiológica nas áreas de fluxo sanguíneo coronário, crescimento do sistema cardiovascular, pulmonar e desenvolvimento neonatal (SWINDLE; SMITH, 1998).

O sistema tegumentar dos suínos assemelha-se ao do ser humano, pois sua pele é relativamente sem pêlos e tem a região epidérmica fixa e ligada firmemente ao tecido subcutâneo, assim como o fornecimento de sangue cutâneo e sequência de eventos na cicatrização de feridas (WOUK et al., 1998). A similaridade na reepitelização e metabolismo cutâneo viabilizam a utilização deste tecido suíno pelas indústrias farmacêutica e cosmética (SWINDLE; SMITH, 1998).

Embora apresente pequenas diferenças morfológicas, o fígado dos suínos tem um metabolismo semelhante ao dos humanos (SWINDLE; SMITH, 1998). Trabalhos relacionados à hemodinâmica hepática, metabolismo da glicose, lactato e glicerol foram desenvolvidos e validados em suínos (DROUGAS et al., 1996).

Os dados da literatura demonstram que o suíno é um modelo animal eficaz em pesquisas, podendo ser amplamente utilizado na busca do conhecimento das afecções que afetam o ser humano. A utilização desse modelo minimiza problemas éticos e a falta de amostras oriundas de seres humanos que se encontra ao estudar esta ou outras espécies (RANDALL; TURTON; FOSTER, 2011).

O cultivo de explantes é uma técnica ainda em aprimoramento, mas eficaz em pesquisas em laboratório. Também denominado método ex vivo, caracteriza-se pelo cultivo de fragmentos de órgãos colhidos com punch de biópsia ou bisturi, incubados em placas com meio de cultura em temperatura semelhante à corpórea, mimetizando as condições do organismo vivo (BANSAL et al., 2009; RANDALL; TURTON; FOSTER, 2011).

Uma das maiores limitações da técnica é a viabilidade celular dos tecidos em relação ao tempo de incubação. Mesmo mimetizando as condições in vivo o tecido é submetido à hipóxia, assim, várias etapas do método têm sido aprimoradas, visando aumentar o tempo de incubação com preservação da viabilidade celular e morfologia do órgão. Dentre essas adaptações, pode-se citar a utilização de diferentes meios de cultura, presença ou ausência de $\mathrm{CO}_{2}$, utilização de diferentes antibióticos e 
incubação estática ou com placas em movimento (RANDALL; TURTON; FOSTER, 2011).

Apesar das limitações, a técnica permite submeter fragmentos de órgãos do mesmo doador a diversos tratamentos, além de controlar as condições ambientais às quais o tecido é submetido. Para sua realização poucos animais são necessários, uma vez que a partir de um animal são produzidos inúmeros explantes. A quantidade de explantes produzidos varia com o órgão utilizado (KOLF-CLAUW et al., 2009; RANDALL; TURTON; FOSTER, 2011). As aplicações descritas para o método utilizando suínos incluem estudos sobre mecanismos de adesão de bactérias a enterócitos (ZHU et al., 1995), efeitos de substâncias cancerígenas sobre o sistema respiratório (MISRA; STEPHAN; CHANDER, 1999), efeitos de medicamentos em doenças articulares (PEARSON; ORTH; LINDNGER,2007), exposição de explantes intestinais a micotoxinas (KOLF-CLAUW et. al., 2009) ou xenobióticos (RANDALL; TURTON; FOSTER, 2011). Assim, apesar de certas limitações, a técnica é adequada para estudos toxicológicos, nutricionais e patológicos.

\section{Histórico do Cultivo de Explantes}

A técnica de cultivo de órgãos foi inicialmente descrita em órgãos de embriões de aves (FELL; ROBISON, 1930). O tamanho reduzido facilita a incubação do órgão inteiro, além dos tecidos embrionários apresentarem maior resistência a hipóxia. Posteriormente, tecidos provenientes de ratos adultos foram cultivados e a viabilidade tecidual dos diversos órgãos cultivados por nove dias foi comparada. A conclusão foi a de que explantes provenientes da traqueia, artérias e ureter apresentavam maior resistência ao tempo de cultivo (TROWELL, 1959). O autor constatou também que a manutenção da pressão de oxigênio e a utilização de aditivos como tiamina e outros aminoácidos ao meio de cultura melhorava a viabilidade celular.

Browning e Trier (1969) fizeram adaptações à técnica, adicionando nutrientes ao meio de cultura, associando a incubação em estufa a $37^{\circ} \mathrm{C}$ com $95 \% \mathrm{O}_{2}$ e $5 \% \mathrm{CO}_{2}$ Assim, pela primeira vez foi possível incubar fragmentos do intestino delgado de humanos por 24 horas, e mesmo com redução na altura de vilosidades estes fragmentos mantiveram a morfologia. Esses estudos ampliaram a aplicação do método, possibilitando a investigação de fatores relacionados à patogênese de doenças, manutenção da homeostase intestinal, produção de enzimas e hormônios, identificação de substâncias tóxicas, proteínas maternas e seus mecanismos de ação para passagem ao feto (BASHA; BAZER; ROBERTS, 1979). O esclarecimento da biogênese das proteínas intestinais (DANIELSEN; SJOSTROM; NOREN, 1983) e análise da capacidade de replicação de enterovírus (HEINZ; CLIVER; DONOHOE, 1987) também foram realizados a partir do emprego do cultivo de explantes.

Os bons resultados observados em tecidos como intestino, que são mais sensíveis à hipóxia, estimulou o emprego da técnica em outras áreas da ciência como a dermatologia, objetivando elucidar os mecanismos envolvidos na reepitelização epidérmica (HEBDA, 1988), na gastroenterologia, para analisar a adesão bacteriana e lesões ocasionadas aos enterócitos por cepas enteropatogênicas de Escherichia coli (ZHU et al.,1995) e na oncologia, para avaliar as lesões que substâncias carcinogênicas, como a nicotina, são capazes de ocasionar à cartilagem nasal (MISRA; STEPHAN; CHANDER, 1999).

Em resumo, a técnica é considerada promissora também para outros ramos da ciência, mesmo com a limitação entre o tempo de incubação e a viabilidade celular. Investigações relacionadas aos efeitos de patógenos, mecanismo de ação de toxinas ou interação parasita-hospedeiro são exemplos de estudos que podem se beneficiar do modelo do explante intestinal.

\section{Vantagens da Técnica}

A técnica de cultivo de explantes mostra-se vantajosa por permitir a redução no número de 
animais utilizados em experimentação laboratorial, uma vez que são produzidos inúmeros explantes a partir de um único doador (KOLF-CLAUW et al., 2009; RANDALL; TURTON; FOSTER, 2011), permitindo ainda maior controle ambiental para experimentação in vitro, quando comparado com o modelo in vivo. A aplicação de doses definidas das substâncias de interesse diretamente no órgão alvo, comparando amostras tratadas e controles provenientes de um único doador, permite a obtenção de resultados mais fidedignos (RANDALL; TURTON; FOSTER, 2011). Este método possibilita a avaliação da morfologia dos órgãos analisados (KOLF-CLAUW et al., 2009), bem como a dosagem de hormônios e mensuração da produção de proteínas (BASHA; BAZER; ROBERTS, 1979) e muco (LLOYD; KENNEDY; MENDICINO, 1984). Essas características tornam o método propício para pesquisas com substâncias tóxicas ou xenobióticos (KOLF-CLAUW et al., 2009; RANDALL; TURTON; FOSTER, 2011) e com patógenos (ZHU et al., 1995; POUCKE et al., 2010).

Associada a essas vantagens, há que se considerar a questão bioética. A sociedade atual exige cada vez mais o controle no uso de animais em experimentação. Nesse sentido, o modelo de cultivo de explantes atende, além dos requisitos éticos, também aos legais. A normatização (decreto 93.933 aprovado em 1987) do Conselho Nacional de Saúde determina que todo estudo deve ser planejado de maneira a obter o máximo de informações utilizando-se o menor número de animais (SCHNAIDER; SOUZA, 2003).

\section{Órgãos de Suínos Utilizados em Explantes}

\section{Intestino}

O intestino é um órgão frágil que desempenha funções vitais a homeostase corporal, portanto tem sido objeto de interesse em estudos que visam elucidar mecanismos fisiopatológicos das doenças intestinais. Os primeiros estudos utilizando fragmentos de intestino foram a partir de íleo incubados por 48 horas para averiguar a replicação de enterovírus em suínos (HEINZ CLIVER; DONOHOE, 1987). Outros estudos utilizando o suíno como modelo animal incubaram explantes de intestino com o objetivo de avaliar os mecanismos de adesão de Escherichia coli em enterócitos. Análises histológicas e ultra-estruturais foram realizadas em explantes de leitões recém-nascidos e desmamados que foram incubados por 4 a 12 horas. A viabilidade tecidual foi comprovada, sendo que os melhores resultados foram observados nos explantes dos animais mais jovens incubados por até oito horas (ZHU et al., 1995; KOLF-CLAUW et al., 2009).

Os efeitos da contaminação por micotoxinas também foram avaliados por meio do modelo ex vivo, utilizando jejuno de suínos (KOLF-CLAUW et al., 2009). O modelo permitiu a análise de alterações histológicas, imunológicas e imunohistoquímicas. A expressão de mitogen activated kinases que compõem vias de sinalização celular também foram analisadas neste modelo (LUCIOLI et al., 2013). Além da possibilidade de analisar os efeitos de mono-contaminações de micotoxinas, o modelo de explantes permite avaliar os efeitos da associação de diferentes patógenos ou substâncias protetoras sobre a mucosa intestinal.

\section{Sistema respiratório}

Explantes de cartilagem nasal de suínos foram utilizados em ensaios sobre os efeitos da nicotina na produção de glicosaminoglicanos, uma vez que pouco se sabe sobre esta ação (MISRA; STEPHAN; CHANDER, 1999). O interesse no modelo do explante de cartilagem advém da possibilidade de expor o tecido a agentes carcinogênicos como a nicotina. Nesse estudo os explantes foram incubados por seis dias, sendo possível comprovar a ação destrutiva da nicotina sobre a cartilagem e a modulação desse efeito pela interleucina-1.

Explantes de traquéia, brônquios e pulmão foram utilizados em estudos sobre os mecanismos 
de replicação dos vírus da influenza humana, aviária e suína. O modelo permitiu analisar a ligação dos vírus aos receptores de membrana celular, bem como a replicação viral em cultivos de 72 horas e demonstrar que os suínos não são a principal espécie para a ocorrência de recombinações gênicas (POUCKE et al., 2010).

\section{Articulação}

Os efeitos da indometacina como antiinflamatório e condroprotetor foram avaliados no cultivo de explantes de articulação em suínos (PEARSON; ORTH; LINDINGER, 2007). Os explantes foram colhidos de maneira asséptica com bisturi da articulação intercarpal e mantidos em meio de cultura por 144 horas. O modelo foi adequado para mimetizar a osteoartrite e comparar a modulação da indometacina e de um extrato herbal sobre a resposta inflamatória na articulação.

Doenças articulares como a osteoartrite são de grande impacto na produção animal, sendo a perda de glicosaminoglicanos um evento precoce nesta afecção. A associação entre a perda de glicosaminoglicanos e a morte de condrócitos após lesão mecânica foi avaliada utilizandose também o modelo ex vivo com articulações (OTSUKI et al., 2008). Explantes de $6 \mathrm{~mm}$ foram cultivados por 48 horas, provenientes da articulação do joelho de suínos de 6 a 9 meses de idade, após serem submetidos a uma única lesão por impacto. A viabilidade celular e a morte celular foram analisadas por exame imuno-histoquímico (anticorpo anti-caspase-3), constatando-se que a diminuição drástica dos glicosaminoglicanos não leva diretamente ao aumento da morte celular.

O modelo ex vivo também permitiu importantes avanços na prevenção e cura de doenças articulares em equinos, uma vez que a utilização desta espécie em experimentos laboratoriais não se mostra viável (PEARSON; ORTH; LINDINGER, 2007).

\section{Endométrio}

Nos suínos, a quantidade de proteína secretada pelo endométrio aumenta drasticamente durante a fase lútea do ciclo estral e no início da gestação, ocorrendo também uma mudança acentuada na composição de proteínas. Estas proteínas formam os constituintes macromoleculares do chamado "leite uterino", responsável pela manutenção do concepto durante a gestação. Uma proteína produzida neste período e de grande importância devido a sua provável função de transporte de ferro da mãe para o feto é uma fosfatase (BASHA; BAZER; ROBERTS, 1979). Estes autores a fim de avaliar se em curto prazo explantes de endométrio de fêmeas suínas prenhes e não prenhes são capazes de sintetizar essa fosfatase in vitro, colheram assepticamente fragmentos de útero no terceiro dia do ciclo estral e em diferentes fases da gestação. Os explantes foram incubados por 24 horas, constatando-se que o endométrio produz e libera esta proteína nas condições de cultivo, ocorrendo declínio na produção após 60 dias de gestação. Estes resultados demonstraram a necessidade da suplementação de ferro de acordo com a fase gestacional dos animais.

\section{Pele}

A similaridade entre a pele humana e suína fomentou o interesse de utilizar explantes de pele em testes de cosméticos. O modelo tem sido utilizado para a avaliação de segurança à exposição cutânea de substâncias químicas (DAME et al., 2008), assim como a avaliação de substâncias antioxidantes solúveis em água, a fim de reduzir os efeitos ocasionados pelos raios ultravioletas à pele (MOISON et al., 2003). O uso da pele de suínos na indústria cosmética colabora no aspecto ético ao reduzir o número de animais em experimentação e evitar testes em animais de laboratório.

Este tecido, quando colhido de maneira asséptica, permite incubações por períodos de até oito dias, com a troca do meio de cultura a cada dois 
dias, o que permite a manutenção da viabilidade celular (DAME et al., 2008). Explantes de 3 a $6 \mathrm{~mm}$ podem ser produzidos com pele colhida do flanco de animais entre seis a nove meses de idade. $\mathrm{O}$ cultivo de pele permite ainda, após o período de incubação que estes explantes sirvam como fonte para cultivo primário de células (DAME et al., 2008; MOISON et al., 2003).

\section{Conclusão}

Explantes de diferentes tecidos de suínos têm sido utilizados na experimentação animal. As finalidades são tão diversas como a ciência: avaliação dos efeitos de substâncias tóxicas, carcinogênicas, terapêuticas, agentes biológicos ou testes de sensibilidade.

O modelo ex vivo é conhecido desde a década de 30, no entanto, nos últimos anos, em decorrência de aspectos éticos e legais foi redescoberto como técnica prática e eficaz. O tempo de incubação com manutenção da viabilidade celular, dependendo do tecido, é um fator limitante desse modelo. Por outro lado, o método permite procedimentos experimentais mais controlados associados à redução no número de animais, ampliando as áreas de investigação científica.

\section{Referências}

BANSAL, D.; AVE, P.; KERNEIS, S.; FRILEUX, P.; BOCHE, O.; BAGLIN, A. C.; DUBOST, G.; LEGUERN, A. S.; PREVOST, M. C.; BRACHA, R.; MIRELMAN, D.; GUILlE, N. N.; LABRUYE, R. E. An ex-vivo human intestinal model to study Entamoeba histolytica pathogenesis. PLOS Neglected Tropical Diseases, New York, v. 3, n. 11, p. 1-11, 2009.

BASHA, S. M. M.; BAZER, W. F.; ROBERTS, M. R. The secretion of a uterine specific, purple phosphatase by cultured explants of porcine endometrium dependency upon the state of pregnancy of the donor animal. Biology of Reproduction, Florida, v. 20, n. 3, p. 431-441, 1979.

BROWNING, T. H.; TRIER, J. S. Organ culture of mucosal biopsies of human small intestine. The Journal of Clinical Investigation, Michigan, v. 48, n. 8, p. 14231432, 1969.
DAME, M. K.; SPAHLINGER, D. M.; SILVA, M.; PERONE, P.; DUNSTAN, R.; VARANI, J. Establishment and characteristics of Gottingen minipig skin in organ culture and monolayer cell culture: relevance to drug safety testing. In vitro cellular \& developmental biology Animal, Berlim, v. 44, n. 7, p. 245-252, 2008.

DANIELSEN, E. M.; SJOSTROM, H.; NOREN, O. Biosynthesis of intestinal microvillar proteins. Pulsechase labelling studies on maltase-glucoamylase, aminopeptidase A and dipeptidyl peptidase IV. Biochemical Journal, London, v. 210, p. 389-393, 1983.

DROUGAS, J. G.; BERNARD, S. E.; WRIGHT, J. K.; SIKA, M.; LOPEZ, R. R.; STOKES, K. A.; WILLIANS, P. E.; PINSON, C. W. A model for the extended studies of hepatic hemodynamics and metabolism in swine. Laboratory Animal Science, Braga, v. 46, n. 6, p. 648$655,1996$.

FELL, H. B.; ROBISON, R. The development and phosphatase activity in vivo and in vitro of the mandibular skeletal tissue of the embryonic fowl. Biochemical Journal, Londres, v. 24, n. 6, p. 1905-1921, 1930.

GARTNER, L. P.; HIATT, J. L. Sistema digestivo: tubo digestivo. In: PEREIRA, D. M. (Trad.). Tratado de histologia em cores. 3. ed. Rio de Janeiro: Elsevier, 2007. p. 387-416.

GUILLOTEAU, P.; ZABIELSKI, R.; HAMMON, H. M.; METGES, C. C. Nutritional programming of gastrointestinal tract development. Is the pig a good model for man? Nutrition Research Reviews, Germany, v. 23, n. 1, p. 4-22, 2010.

HEBDA, P. A. Stimulatory effects of transforming growth factor-beta and epidermal growth factor on epidermal cell outgrowth from porcine skin explant cultures. The Journal of Investigative Dermatology, Pennsylvania, v. 91, p. 440-445, 1988.

HEINZ, B. A.; CLIVER D. O.; DONOHOE, B. Enterovirus replication in porcine ileal explants. Journal of General Virology, Great Britain, v. 68, p. 2495-2499, 1987.

KOLF-CLAUW, M.; CASTELlOTE, J.; JOLY, B.; BOURGES-ABELLA, N.; RAYMOND-LETRON, I.; PINTON, P.; OSWALD, I. P. Development of a pig jejunal explant culture for studying the gastrointestinal toxicity of the mycotoxin deoxynivalenol: histopathological analysis. Toxicology in Vitro, Roma, v. 23, n. 8, p. 15801584, 2009.

LLOYD, C.; KENNEDY, J. R.; MENDICINO, J. Regulation of the synthesis of mucin glycoproteins in swine trachea explants. In Vitro, Georgia, v. 20, n. 5, p. 416-432, 1984.

LUCIOLI, J.; PINTON, P.; CALLU, P.; LAFFITTE, J.; 
GROSJEAN, F.; KOLF-CLAUW, M.; OSWALD, I. P.; BRACARENSE, A. P. F. R. L. The food contaminant deoxynivalenol activates the mitogen activated protein kinases in the intestine: interest of ex vivo models as an alternative to in vivo experiments. Toxicon, France, v. 66, p. 31-36, 2013.

MISRA, R.; STEPHAN, S.; CHANDER, C. L. The ability of nicotine to induce glycosaminoglycan release in porcine nasal cartilage explant cultures. Inflammation Research, Basel, v. 48, n. 2, p. S119-S120, 1999. Suplemento 2 .

MOISON, R. M. W.; RIJNKELS, J. M.; PODDA, E.; RIGHELE, F.; TOMASELLO, F.; CAFFIERI, S.; VAN HENEGOUWEN, G. M. J. B. Topically applied vitamin $\mathrm{C}$ and cysteine derivatives protect against UVA-induced photodegradation of suprofen in ex vivo pig skin. Photochemistry and Photobiology, Malden, v. 77, n. 4, p. 343-348, 2003.

OTSUKI, S.; BRINSON, D. C.; CREIGHTON, L.; KINOSHITA, M.; SAH, R. L.; D'LIMA, D.; LOTZ, M. The effect of glycosaminoglycan loss on chondrocyte viability. Arthritis \& Rheumatism, California, v. 58, n. 4, p. 1076-1085, 2008.

PEARSON, W.; ORTH, M. W.; LINDINGER, M. I. Differential anti-inflammatory and chondroprotective effects of simulated digests of indomethacin and an herbal composite (Mobility TM) in a cartilage explant model of articular inflammation. Journal of Veterinary Pharmacology and Therapeutics, Bristol, v. 30, n. 6, p. 523-533, 2007.

POUCKE, S. G. M. V.; NICHOLLS, J. M.; NAUWYNCK,
H. J.; REETH, K. V. Replication of avian, human and swine influenza viruses in porcine respiratory explants and association with sialic acid distribution. Virology Journal, Bélgica, v. 7, p. 1-14, 2010.

RANDALL, K. J.; TURTON, J.; FOSTER, J. R. Explant culture of gastrointestinal tissue: a review of methods and applications. Cell Biology and Toxicology, London, v. 27 , n. 4 , p. 267-284, 2011.

SCHNAIDER, T. B.; SOUZA, C. Aspectos éticos da experimentação animal. Revista Brasileira de Anestesiologia, Rio de Janeiro, v. 2, p. 278-285, 2003.

SWINDLE, M. M.; SMITH, A. C. Comparative and physiology of the pig. Scandinavian Journal of Laboratory Animal Science, Escandinávia, v. 25, p. 1121, 1998. Supplement 1.

TROWELL, O. A. The culture of mature organs in a synthetic medium. Experimental Cell Research, Suécia, v. 16, n. 1, p. 118-147, 1959.

WOUK, A. F. P. F.; DINIZ, J. M.; CÍRIO, S. M.; SANTOS, H.; BALTAZAR, E. L.; ACCO, A. Membrana biológica (biofill) - Estudo comparativo com outros agentes promotores da cicatrização da pele em suínos: aspectos clínicos, histopatológicos e morfométricos. Archives of Veterinary Science, Curitiba, v. 3, n. 1, p. 3137, 1998.

ZHU, H.; HAREL, J.; JACQUES, M.; FAIRBROTHER, J. M. Interaction with pig ileal explants of Escherichia coli 045 isolates from swine with post weaning diarrhea. Canadian Journal of Veterinary Research, Canadá, v. 59, n. 2, p. 118-123, 1995. 
